\title{
Mais-Valia ou Mais-Valor?
}

\section{Adriano Lopes Almeida Teixeira ${ }^{a}$}

Resumo: O presente artigo busca analisar as razões e as eventuais consequências de um movimento em curso na literatura econômica marxista no Brasil que é a troca da expressão mais-valia por mais-valor. Partindo da discussão feita por Mário Duayer sobre o caráter ontológico da crítica de Marx, argumenta-se que a expressão mais-valia é mais funcional e adequada para as diversas interpretações da obra de Marx. Mais do que uma análise da semântica envolvida na troca dos termos, o que se pretende é iluminar o caráter ontológico da crítica de Marx na teoria da mais-valia, trazendo a lume a impertinência e inadequação da substituição, a essa altura do debate, da expressão mais-valia por mais-valor.

Palavras-chave: Mais-Valia; Mais-Valor; Crítica Ontológica; Método Dialético; Semântica. Classificação JEL: B14; B41; B51

\begin{abstract}
This article seeks to analyze the reasons and possible consequences of an ongoing movement in the economic Marxist literature in Brazil that is the exchange of the expression mais-valia by mais-valor. Starting from the discussion made by Mário Duayer about the ontological character of Marx's critique, it is argued that the expression "surplus value" is more functional and adequate for the various interpretations of Marx's work. Rather than an analysis of the semantics involved in the change of terms, what is intended is to illuminate the ontological character of Marx's critique in the surplus value theory, bringing to light the impertinence and inadequacy of replacing, at this point in the debate, the expression of value added.
\end{abstract}

Keywords: Surplus Value; Additional Value; Ontological Critique; Dialectical Method; Semantic.

${ }^{a}$ Doutor em Economia pela UFMG/CEDEPLAR. Professor Adjunto do Departamento de Economia da Universidade Federal do Espírito Santo. E-mail: adriano.teixeira@ufes.br 


\section{Introdução}

A história do pensamento econômico se alimenta de duelos travados entre perspectivas teóricas diferentes, visões de mundo alternativas, desavenças metodológicas, inquietações, desconfianças e questões das mais variadas ordens. Recentemente, Mário Duayer, um conhecido estudioso da obra de Marx no Brasil, pretendeu encerrar uma polêmica ao sugerir a interdição do debate em torno de uma dessas questões aparentemente de menor porte. Trata-se da substituição da conhecida tradução para a língua portuguesa do termo alemão Mehrwert, a saber, mais-valia, pela expressão mais-valor.

Segundo Duayer (2011a, p. 23), não há como justificar a conhecida tradução para a língua portuguesa do termo alemão Mehrwert como mais-valia. Por esse ponto de vista, a estrada teórica que conduz à mais-valia estaria interditada, pois, segundo ele, "uma vez que não é tradução literal de "Mehrwert", o uso de "mais-valia" teria de ser justificado teoricamente. Essa tarefa é impossível. " E assim, teríamos chegado ao fim da história da expressão mais-valia.

Um sentimento não confessado, uma mistura de incômodo com constrangimento, surgiu entre alguns marxistas (e também entre estudiosos de Marx) no Brasil. Trata-se de um mal-estar causado entre eles a partir da tradução dos Grundrisse para a língua portuguesa em 2011, que foi o estopim para uma série de publicações de obras marxistas em que aquela categoria aparece traduzida como mais-valor.

Além de Claus Germer e Pedro Leão da Costa Neto (2012) que, em texto que será retomado mais à frente, expressam de forma polida a insatisfação com o procedimento, Eleutério Prado (2012, p. 02) mantém o mesmo tom, referindo-se à publicação no Brasil dos cinco primeiros cadernos do Manuscrito de 1861-1863 feita por Leonardo de Deus, quando diz que o tradutor "preferiu, contra toda uma tradição já consagrada, denominar essas duas últimas categorias de mais-valor absoluto e de mais-valor relativo."

Menos contida é a observação feita por Lessa ${ }^{1}$ :

Um certo modismo, um exagerado apego à importância de ser original, somados ao culto da novidade e alguns interesses editoriais, fizeram com que, em algumas traduções recentes dos textos de Marx, mais-valia venha traduzida por mais-valor. Não se impressione, caro leitor, é a mesma categoria de Marx traduzida de uma forma novidadesca.

Portanto, parece estranho o consenso sugerido por Duayer (2011b)2:

A tradução de "Mehrwert" por mais-valor em lugar de mais-valia é teoricamente indiscutível. No entanto, antes de adotá-la consultei vários pesquisadores brasileiros que trabalham no interior da tradição marxista. A opinião unânime foi de que o uso de mais-valor é de fato irreparável do ponto de vista teórico.

Diante de certos consensos estabelecidos numa determinada área do conhecimento, parece que uma tentativa inusitada de contestação necessita de uma porta de entrada

\footnotetext{
${ }^{1}$ Não foi possível determinar a data de publicação do referido artigo de Lessa.

${ }^{2}$ Essa citação consta de entrevista dada por Duayer ao Jornal Estadão, conforme nos lembra Pires (2011) em seu blog, em artigo com o mesmo título do presente trabalho.
} 
alternativa, já que, se Duayer estiver correto, o acesso pelas vias teóricas está cerrado. É necessário, pois, tentar entender as razões do incômodo, ou desse estranhamento.

De fato, na vida acadêmica é comum surgirem inquietações e inconformismos teóricos mesmo antes de se desvelar suas razões. São incômodos que geralmente só são contornados depois de intenso trabalho de análise e de pesquisa. Por outro lado, tem-se a impressão de que o artista ou o literata conhece caminhos mais curtos e diretos, e, despudoradamente, percorre atalhos que na vida acadêmica não são admitidos.

A inclinação constante de Marx a metáforas, a textos poéticos e a todo tipo de recurso linguístico não significava desvio da ciência. Com efeito, somos frequentemente surpreendidos por reflexões não científicas que expressam ideias tão instigantes quanto as que são obtidas pelo veio da ciência. Por certo, não se deve subestimar, e nem Marx subestimava, o conselho dos poetas ou qualquer centelha de inspiração advinda de obras literárias.

Encantado com a forma como os grandes escritores conseguiam captar e expressar através de suas obras a essência das coisas, o modo de ser da sociedade, as contradições do real e seus reflexos no comportamento dos homens, por uma via que não seguia os trâmites do universo científico, Marx abraça a literatura como ferramenta inescapável do conhecimento humano, embora reconheça seu papel meramente acessório no processo de elaboração teórica.

Guardadas as devidas proporções em relação aos recursos estilísticos de Marx, foi pelo encontro casual com um texto literário daquele teor, que me surgiu a motivação para enfrentar um desses maneirismos que vez ou outra ameaçam, bem ou mal, tradições consolidadas, e que, no caso em questão, consiste em substituir na literatura marxista o "defeituoso" termo mais-valia pelo "virtuoso" mais-valor.

Trata-se de uma carta escrita por Clarice Lispector a sua irmã, em janeiro de 1947 , que aparentemente necessitava receber algumas palavras de consolo e de elevação da autoestima. A certa altura, como querendo estimular sua irmã a conviver com suas próprias idiossincrasias, Clarice diz: "até cortar os defeitos pode ser perigoso - nunca se sabe qual o defeito que sustenta nosso edifício inteiro." Mais à frente, acrescenta: "Nem sei explicar, querida irmã, minha alma. Mas o que eu queria dizer é que a gente é muito preciosa, e que é somente até certo ponto que a gente pode desistir de si própria e se dar aos outros e às circunstâncias."3

À guisa da carta de Clarice Lispector a sua irmã, este artigo invoca uma certa liberdade de forma, para fazer chegar aos estudiosos de Marx um clamor pela reabilitação da mais-valia. Como imitação de uma carta a alguém tão familiar como a expressão maisvalia - que também não pode desistir de si própria - é resultado de uma inquietação perante algo aparentemente trivial, uma simples alteração terminológica. Não se pretende aqui superdimensionar a discussão, problematizar uma falsa questão, fantasiar uma patologia apenas para valorizar a prescrição do remédio.

\footnotetext{
${ }^{3}$ Grande parte da carta está reproduzida em biografia da autora escrita por Benjamin Moser (2013) e em blog dedicado a ela: http:/claricelispector.blogspot.com.br/2008/02/carta.html.
} 
O ponto central do argumento em favor da substituição de mais-valia por mais-valor é que isso seria, do ponto de vista semântico, mais lógico e mais adequado, já que expressa uma quantidade de valor extraída além da que seria o valor da força de trabalho. Segundo seus defensores, o termo tradicionalmente usado padece de um defeito grave, e, portanto, tal alteração seria potencialmente mais compreensível para quem não estivesse familiarizado com a obra de Marx, tendo em vista que o termo mais-valia parece não guardar nenhuma relação de "parentesco" com o termo valor.

Pelo que se sabe, o pontapé inicial foi a tradução brasileira dos Grundrisse por Mário Duayer, procedimento seguido em recentes traduções da Editora Boitempo, e também incorporada em tradução dos Manuscritos de 1861-1863 de Marx feita por Leonardo Gomes de Deus. Embora seja uma simples remodelagem semântica, o que se mostra indiscutível é que, mesmo parecendo estar diante de algo inofensivo e não prejudicial, uma certa inquietação atingiu marxistas "tradicionais" que se mostraram desconfortáveis com essa mudança, mas que, quando protestaram, não tiveram ressonância. ${ }^{4}$

A primeira impressão que se nos apresentou foi a do conhecido apego às tradições ou uma habitual resistência às mudanças. Como já dito, é comum que as sensações apareçam antes de suas explicações. Porém, no caso em tela, foi questão de tempo para surgir a suspeita de que aquele incômodo se devesse a algo mais específico: o uso da expressão mais-valor como resultado de um tecnicismo semelhante ao de termos como valor agregado, reserva de valor, liquidez, termos que não reproduzem a riqueza do universo categorial marxista, mas que, se incorporados, na visão de alguns, facilitariam o entendimento da categoria ${ }^{5}$ e, quiçá, o diálogo com a teoria econômica convencional.

Não significa que seja vedado fazer aprimoramentos, nem que a teoria de Marx não seja passível de reinterpretações, mas é fato que o pensamento econômico marxista ao longo do século XX se ressentiu de suas tradições e de um movimento típico e necessário para nutrir as bases de qualquer escola do pensamento, que é a continuidade do exercício teórico entre os seus seguidores, tanto na tradição marxista, quanto na marxologia. Por diversas vicissitudes, não deram continuidade aos trabalhos teóricos em seus campos, seja porque importantes obras de Marx só se tornaram disponíveis a partir de 1932 - os Grundrisse notadamente, só a partir de 1939/41 - seja porque eram vítimas do boicote americano ou das ações letais do regime stalinista. Para ficar em alguns poucos exemplos, Lenin e Rosa Luxemburgo morreram nos anos 20, enquanto David Riazanov e Isaac Rubin foram executados na década seguinte. Na verdade, o século XX ficou marcado por um embate célebre entre liberais e keynesianos, que se alternaram como polos hegemônicos. Esses últimos assumiram o centro do palco após a grande depressão dos anos 20, sendo deslocados pelos primeiros a partir dos anos 70 até os dias atuais.

Contrariando a tendência, preferimos continuar usando o termo mais-valia, pelas razões que serão expostas. Pode-se até dizer que são razões que se fundam mais na tradição

\footnotetext{
${ }^{4}$ Refiro-me especialmente ao texto do Germer e Neto (2012), "Em torno da tradução brasileira dos Grundrisse”, publicado na Revista Crítica Marxista.

${ }^{5}$ A argumentação de Mário Duayer (2011a, p. 23) restringe-se a esse ponto, ou seja, a busca por uma melhor compreensão de algo que é enigmático.
} 
consolidada e no significado peculiar dessa categoria na teoria de Marx do que na própria pertinência semântica do termo. Por isso, a etimologia do termo ficará em segundo plano. Ou seja, a perspectiva da discussão não será sobre o que Marx deveria ter feito no seu próprio idioma ou com a adequação semântica da escolha inicial feita por ele do termo Merhwert ${ }^{6}$ para designar a exploração do trabalhador. Também não nos preocuparemos em localizar algo como o elo perdido, o porquê do primeiro tradutor de $O$ capital para o português ter escolhido o termo mais-valia. Como já dito, o nosso enfoque está em, tendo sido adotados aqueles procedimentos no passado (refiro-me ao termo usado pelo próprio Marx para a categoria e ao termo que foi escolhido inicialmente nas traduções brasileiras), investigar o sentido da mudança do termo na língua portuguesa, a essa altura do debate.

Nesse sentido, começaremos tentando evidenciar a problemática em torno dessa questão na próxima seção, fazendo algumas considerações sobre o processo de construção de categorias em Marx, para ressaltar o caráter ontológico de sua crítica, que teve, a nosso ver, seu clímax na descoberta da mais-valia, uma categoria que rejeita de per si as benesses da obviedade. Na terceira seção, a problemática apresentada inicialmente será enfrentada, com um balanço das vantagens e/ou desvantagens da referida troca, seguindo-se, então, as considerações finais.

\section{O Caráter Ontológico da Crítica de Marx}

Ironicamente, a questão central desta seção está inspirada em um artigo do Mário Duayer (2012) sobre a crítica ontológica em Marx, tema discutido por ele em diversos textos publicados. Para defender sua tese, Duayer recorre a elementos da filosofia da ciência, tomando as teorias mais conhecidas, como as de Khun e de Lakatos, para desenvolver sua argumentação. Segundo ele, tanto as noções de paradigma, em Khun, e de núcleo rígido dos programas de pesquisa científica, em Lakatos, pressupõem uma determinada ontologia, e, nesse sentido, os desenvolvimentos científicos preconizados pelas duas perspectivas ocorrerão sem prejuízo dos axiomas fundantes e estruturais dos respectivos sistemas teóricos. O que importa, no caso, é o desenvolvimento dos sistemas teóricos que ampliem suas capacidades de explicar o terreno empírico, não havendo, portanto, crítica entre princípios teóricos distintos que, por definição, pertencem a visões de mundo distintas e incomensuráveis.

É nesse sentido que Duayer defende que a crítica de Marx é crítica ontológica, pois a crítica da economia política desse autor significou uma crítica da sociedade capitalista, da própria sociabilidade do capital. Marx construiu sua crítica por um processo de elaboração teórica que requeria o diálogo permanente com outras estruturas teóricas, que

\footnotetext{
${ }^{6} \mathrm{Na}$ Werke (1981, p. 135), consta o termo Mehrwert já na primeira vez em que Marx faz referência ao "valor adicional", embora naquele momento (1842) ele estivesse ainda muito distante da descoberta e do significado da mais-valia enquanto categoria teórica. No Collected Works, os tradutores da Werke para o inglês escolheram o termo additional value, e não surplus-value, como faria o próprio Marx nos Manuscritos de 1861-1863. (Marx e Engels, 1975, p. 250).
} 
significava, ao mesmo tempo, confronto, incorporação, rejeição e consequente suprassunção. Inspirado em Postone, Duayer conclui então, que a crítica precisa ser feita ao modo de produzir sob o capital, especificamente, ao trabalho no capitalismo, e não ao capitalismo do ponto de vista do trabalho.

No mesmo sentido, deve-se ressaltar que Marx foi extremamente cauteloso quanto à apropriação de elementos do pensamento científico de sua época, seja quanto à filosofia clássica alemã, seja quanto à economia política clássica. De fato, Marx relutou em publicar seu livro de Economia por entender que os elementos teóricos e metodológicos precisavam ser burilados a ponto de não comprometer a exposição de suas descobertas. Ele insistia na elaboração de uma visão de mundo que não fosse mera continuidade ou mero aperfeiçoamento do que já tinha sido feito pelos filósofos e pelos economistas. Tratava-se de construir um edifício teórico alternativo, para o qual os elementos de sua construção seriam minuciosamente escolhidos, tanto no seu conteúdo, quanto na sua forma de apresentação.

Em suma, Marx não tergiversava, nem titubeava com detalhes aparentemente insignificantes. Os elementos que constituiriam sua crítica, embora oriundos da filosofia de sua época e da economia política inglesa, precisavam passar pela filtragem do método dialético. Para ilustrar um desses momentos, o Marx de A Miséria da Filosofia, ainda estava preso à categoria valor como princípio teórico fundamental, que, como em Ricardo, significava apenas "uma das dimensões da sociabilidade burguesa, a da igualdade..." e, por isso, não captava "o sentido profundo das relações sociais no capitalismo, que tem tanto de igualdade quanto de desigualdade." (Coutinho, 1997, p. 41).

O que Coutinho está querendo indicar é a ausência em A Miséria da Filosofia de uma ontologia específica, a teoria do capital como relação social criadora de riqueza, noção que só poderia ser conquistada com a incorporação da dimensão da desigualdade, consumada na descoberta da mais-valia nos Grundrisse. Se Marx parasse ali, se não rompesse com a perspectiva ontológica do constructo ricardiano, teria sido mais do mesmo, apenas mais um economista clássico.

Pode parecer exagerada e desproporcional a comparação entre, de um lado, as aquisições teórico-metodológicas de Marx fundamentais para elaboração de sua crítica e, de outro uma questão de menor vulto, a saber, os eventuais prejuízos para o universo categorial marxista do uso da expressão mais-valor em substituição à mais-valia. Até admitimos que talvez seja possível que a referida mudança não traga danos aos trabalhos daqueles teóricos que já se apropriaram do universo conceitual de Marx. O que se argumenta, porém, é que tal movimento, se não atrapalha, no mínimo não ajuda a consolidar uma tradição favorável a um crescente engajamento no processo de elaboração teórica no campo marxista, no mesmo sentido da argumentação de Germer e Neto (2012) que, pelo que se sabe, foram os primeiros a protestar formalmente contra a mudança supramencionada. ${ }^{7}$

\footnotetext{
7 Esses autores exaltam a tradução brasileira dos Grundrisse, mas apontam algumas imprecisões em determinadas expressões, entre elas, o mais-valor. Não desenvolvem o argumento quanto a esse ponto
} 
Defendendo a continuidade do uso da expressão mais-valia, eles afirmam que

semelhante opção coloca os marxistas - e não somente - frente ao dilema da elaboração e constituição de um vocabulário: a opção pela introdução de inovações no vocabulário ou a relação com a tradição consolidada, quando essa última não representa um sério obstáculo ou até mesmo um equívoco conceitual. (Germer e Neto, 2012, p. 166).

Fazem menção ainda das observações feitas por Romano Garcia (2007, p. 12) no prefácio de sua tradução espanhola de El Capital:

Quanto aos termos mesmos, temos decidido pelos que já tem reconhecimento na terminologia marxista em nossa língua. Assim, cremos que a expressão "mais-valia" traduza com suficiente clareza o conceito expressado em alemão por Marx "Mehrwert", sem que haja necessidade de inventar outro tal como "mais-valor".

Ademais, não é provável que o uso da expressão "mais-valor" diminua o caráter enigmático desta categoria, como sugere Duayer (2011, p. 23), ao dizer que a manutenção do termo "mais-valia", "converteria uma categoria de simples compreensão em algo enigmático".

É bastante provável que a escolha da expressão mais-valia nas duas primeiras traduções de $O$ capital para o português no Brasil tenha sido influenciada pelas traduções espanholas. Tanto a tradução feita por Reginaldo Sant'ana em 1968 (Bertrand Brasil), quanto a feita por Flávio R. Kothe, Paul Singer e Régis Barbosa em 1983 (Abril Cultural) optaram pelo uso de mais-valia. Somente esses últimos justificaram o porquê da escolha:

Adotou-se como norma utilizar as expressões marxistas vertidas ao português por economistas, sociólogos, filósofos etc. e de uso corrente, de modo a facilitar a compreensão do texto. Pareceunos que seria um purismo injustificável retraduzir por exemplo Mehrwert por mais-valor (em analogia com mais-trabalho e mais-produto), quando a expressão mais-valia é o vocábulo consagrado em português. (Kothe, Singer e Barbosa, 1983, p. 4-5). ${ }^{8}$

Em língua espanhola, foram feitas algumas traduções incompletas ou parciais de $O$ capital desde o início do século passado, mas foi com a respeitada tradução de Wenceslao Roces para a Fondo de Cultura, em $1946^{9}$, que o estudo de $O$ capital pôde ser feito de forma mais rigorosa e sistemática. Como nos lembram Germer e Neto (2012, p. 166), Roces opta por plusvalia, no que é seguido pelas traduções de Manuel Sacristán pela Grijalbo e de Vicente Romano pela Akal, ambas em 1976, sendo contra-arrestada apenas pela tradução de Pedro Scaron em 1975 para a Siglo XXI, que opta pelo termo plusvalor.

Scaron (1975, p. XVIII) explica sua opção quando da tradução de $O$ capital. Ele diz que traduziu nos Grundrisse os sinônimos Mehrwert e Surpluswert por plusvalia e plusvalor respectivamente, mas que, em $O$ capital, como só aparece Mehrwert, ele optou por traduzi-lo como plusvalor pela "transparência" do termo, pela ligação morfológica

específico, apenas remetendo o leitor ao artigo de Balibar e Lefebvre (1978). Alguns dos argumentos apresentados por estes últimos serão objeto da seção três do presente artigo.

${ }^{8}$ Note que, se Duayer acha injustificável a tradução de Mehrwert por mais-valia, os tradutores da segunda versão de $O$ capital para o português do Brasil também acham injustificável o uso de mais-valor. O curioso é que ambos pretendem com suas escolhas facilitar o entendimento do leitor.

${ }^{9}$ Já em 1934-35, foi publicada a tradução do tomo I de $O$ capital por Wenceslao Roces para a Editorial Cenit. 
entre termos como valor e plusvalor, com justificativas semelhantes às de Duayer. Curiosamente, em suas notas nos Grundrisse, Scaron (2006, p. VIII) sugere que o uso alternado que fez de plusvalia e plusvalor deu-se por conta do caráter de rascunho da obra e por respeitar a linguagem filosófica hegeliana que ali foi empregada em muitos momentos. Segundo ele, alguns desses termos encontrariam caráter definitivo em $O$ capital, quando então apareceriam como termos "técnicos". Podemos deduzir, então, que para ele, Mehrwert tem em $O$ capital um conteúdo mais técnico do que propriamente filosófico.

Scaron parece restringir as potencialidades da mais-valia como categoria teórica fundamental da crítica de Marx, ao contrário de Dussel (2008, p. 21), que qualifica essa categoria como "complexa, ou seja, supõe em sua construção (fruto de um desenvolvimento teórico-produtivo) muitas outras categorias mais simples."

Dessa forma, a sumária descrição dos elementos postos por Duayer, já nos permite inferir que a substituição da expressão mais-valia por mais-valor não é necessariamente um ajuste ingênuo e inofensivo. ${ }^{10}$ Parece, inclusive, caminhar na direção contrária, por querer tornar algo - que aparece de forma mistificada na superfície do sistema (como lucro, juros e renda), e que é envolto por um manto enigmático e obscurecedor qualquer que seja seu nome - em algo evidente e decifrável por si só. Obviamente, isto não contribui para a construção de uma crítica que seja ontológica, e, ao contrário do defendido pelo autor - por sinal, amplo conhecedor da obra de Marx e do significado da mais-valia para sua teoria constitui-se apenas em um elemento de crítica do capitalismo do ponto de vista do trabalho, de seu aspecto quantitativo, decorrente dos mecanismos usados no sistema para explorar o trabalho o máximo possível, fazê-lo produzir mais valor além do que seria razoável.

Note que a simples retirada do hífen não altera o sentido da expressão. Mais valor e mais-valor acabam sendo equiparados, termos tomados como iguais, e assim, uma palavra se iguala a uma categoria econômica que foi descoberta a muito custo, quando se sabe que Marx não procurava construir palavras ou conceitos, mas sim, categorias. ${ }^{11}$

Buscando aceitação, retira-se o que é enigmático, aparam-se as garras, amansa-se a fera, para remodelar a expressão, tornando-a palatável e inofensiva. Quiron, o centauro, volta a ser somente cavalo, perde sua humanidade, e assim, sucumbimos mais uma vez, recebendo como recompensa a uniformização do diálogo com o mundo dos neoclássicos, onde não há homens, nem história, nem relações sociais, mas apenas cálculos instintivos.

Reitere-se que o que está em jogo aqui não é a ideia de que a expressão mais-valia encerra um tipo de substância que não pode ser carregado pela expressão mais-valor. Com efeito, como bem lembra De Deus (2010a, p. 17), existe sinonímia entre os dois termos.

\footnotetext{
${ }^{10}$ Sobre isto, vale lembrar o longo prefácio escrito por Engels quando da publicação do livro II de $O$ capital em 1885, que se preocupa em mostrar o que distinguiu a teoria da mais-valia de Marx de todas as outras supostas teorias que apontavam para uma extração em favor do patrão de parte do valor produzido pelo trabalhador, especialmente quanto à elaboração teórica de Rodbertus.

${ }^{11}$ Em conhecida passagem sobre o tema, Marx diz que não começa de "conceitos", nem do "conceito de valor", mas da "forma social mais simples em que se corporifica o produto do trabalho na sociedade atual, que é a “mercadoria." (Marx, 1977, p. 176).
} 
Mas, em seguida, ele apresenta mais um motivo justificador da troca do termo mais-valia por mais-valor: "o uso corrente dessas duas palavras é bastante diverso." Ou seja, segundo ele, ao contrário do termo valia, o termo valor é bastante conhecido das pessoas no seu dia a dia, o que no seu entendimento, podemos deduzir, facilitaria ${ }^{12}$ o acesso ao significado e papel daquela categoria na obra de Marx.

Ora, é justamente o contrário. É bom que seja diferente, que chame a atenção, que se ouça o termo como expressão de uma visão de mundo não apreensível diretamente, embora haja risco desse obstáculo desanimar potenciais candidatos a estudar Marx. As categorias em Marx (1986b, p. 18) "exprimem portanto formas de modos de ser, determinações de existência, frequentemente aspectos isolados dessa sociedade determinada, desse sujeito." Suas categorias não são ideias geradas a partir da consciência; elas expressam traços, aspectos do mundo real, determinações próprias das relações sociais capitalistas. Daí o embaraço por ele indicado: "Nosso embaraço se origina talvez de que tenhamos tomado as pessoas apenas como categorias personificadas e não individualmente." (Marx, 1983a, p. 136).

O termo mais-valor, portanto, parece "desontologizar" a categoria, esvaziando-a de sua genética marxista, e assim, caminhando na mesma direção dos clássicos que naturalizaram suas categorias econômicas.

Embora bastante instigante a discussão feita por Duayer sobre o caráter ontológico da crítica de Marx, com a qual concordamos, deixaremos o campo da filosofia da ciência para sugerir, en passant, que a crítica ontológica de Marx pode também ser reafirmada pela relação que ele estabeleceu com a economia política clássica. Marx sempre foi dialogal, sem nunca, entretanto, incorporar o sotaque dos economistas políticos.

De fato, Marx não foi um economista clássico, e isso está relacionado ao fato do objeto de pesquisa dele ser diferente, constituindo uma nova ontologia. ${ }^{13}$ Lukács adverte para a necessidade de não negligenciar o método de Marx, pois, segundo ele, tal descuido levou a um predomínio das questões epistemológicas em Marx, com consequente abandono ou "negligência da crítica da economia política e sua substituição por uma economia simples entendida como ciência no sentido burguês". ${ }^{14}$ (Lukács, 2012, p. 260).

Sendo os clássicos portadores de uma visão de mundo específica, é à construção teórica por eles elaborada que se dirige a crítica de Marx, por seu turno, uma crítica ontológica. O exercício feito por Marx foi a depuração das verdades científicas apresentadas pelos clássicos, que, segundo ele, "serão sempre paradoxais, se julgadas pela experiência de todos os dias, a qual somente capta a aparência enganadora das coisas."

\footnotetext{
${ }^{12}$ É difícil imaginar que Marx adotasse a mudança em questão como estratégia para facilitar a compreensão de sua obra. Ele finaliza o prefácio da edição francesa com a seguinte observação: "Não há entrada já aberta para a ciência e só aqueles que não temem a fadiga de galgar suas escarpas abruptas é que têm a chance de chegar a seus cimos luminosos." (Marx, 1983b, p. 23).

${ }^{13}$ Para as duas temáticas mencionadas, a saber, a constituição da crítica da economia política de Marx, e sua relação com os economistas clássicos, ver os artigos de Aloisio Teixeira (2000) e Adriano Teixeira (2019), respectivamente.

${ }^{14} \mathrm{Na}$ terceira seção, abordaremos o mais-valor como um movimento de aburguesamento da categoria econômica.
} 
(Marx, 1986a, p. 158). Eles não seriam portadores de um método capaz de levá-los a ultrapassar a esfera aparencial, tendo em vista que, pelo recurso de generalizações mentais, cometem arbitrariedades na escolha de categorias e procuram "pela análise reduzir as diferentes formas de riqueza, fixas e estranhas entre si, à unidade intrínseca delas, despojálas da configuração em que existem lado a lado, independentes umas das outras." (Marx, 1985, p. 1538).

Embora Marx tenha se beneficiado da análise feita anteriormente pelos clássicos de categorias como o capital, o uso que ele faz daquele legado ocorre no âmbito de uma visão de mundo diferente, demarcando os limites de uma nova ontologia. Como eles não penetram, nem tem interesse em, acabam por naturalizar as relações sociais do modo de produção capitalista. Por isso, em obra escrita antes de $O$ capital, Marx pontua:

A economia clássica não tem interesse em analisar como nascem as diferentes formas, mas em convertê-las, pela análise, à unidade delas, pois parte dessas formas como pressupostos dados. Mas a análise é o requisito indispensável para se revelar a gênese, para se compreender o processo real de formação nas diferentes fases. Por fim, a economia clássica é falha e carente ao conceber a forma básica do capital - a produção destinada a se apropriar do trabalho alheio - não como forma histórica e sim como forma natural da produção social [...].(Marx, 1985, p. 1538).

Por isso, diz-se que Marx não foi um economista político, mas um crítico da economia política (Heinrich, 2004, p. 33), pois o objeto não é conhecido a priori, mas precisa ser acompanhado, investigado e apropriado, visando à elaboração de uma teoria sobre o modo de ser do capitalismo que é também uma teoria sobre o modo como esse sistema se apresenta. A mais-valia é o elemento vivo dessa construção. Devido a ela, pôde Marx avançar na instauração de sua crítica. ${ }^{15}$

\section{Mais-valia x Mais-valor}

O debate em torno dessa questão ainda não foi instaurado no Brasil, e talvez não venha a ser. É possível que as pechas de tradicionalista ou de ultrapassado gerem nos insatisfeitos uma tendência passiva de aceitação do mais-valor. Mas debate fervoroso aconteceu em outros países ao longo das últimas décadas, especialmente na França, que teve Balibar e Lefebvre com um dos textos mais representativos dessa discussão, Plusvalue ou survaleur?, de $1978 .^{16}$

\footnotetext{
15 A rigor, a descoberta da mais-valia acontece nos Grundrisse, mas é em $O$ capital que sua constituição e localização no edifício teórico de Marx encontram uma exposição melhor organizada. Para uma análise minuciosa da descoberta, originalidade e importância da categoria da mais-valia na crítica da economia política feita por Marx, ver Teixeira (2014).

${ }^{16} \mathrm{O}$ texto de Balibar e Lefebvre se destacam pelo pioneirismo, mas é preciso destacar que o debate avançou em publicações não examinadas no presente artigo, como destacam Germer e Neto (2012, p. 166): "Essa mesma opção foi utilizada na recente tradução de Gérard Cornillet, Laurent Prost e Lucien Sève do Le chapitre VI Le capital (Editions Sociales, 2010) nos quadros do projeto Grande édition Marx et Engels (GEME). Os tradutores fornecem uma breve análise da polêmica francesa sobre a referida tradução, na qual registram as
} 
Balibar e Lefebvre (1978, p. 37) questionam a tradução feita do livro I de $O$ capital para o francês por Joseph Roy, ainda no tempo de Marx, do termo alemão Mehrwert (mehr $=$ mais, wert $=$ valor ou valia) por plus value, sugerindo sua substituição pelo termo survaleur. Explicam que Roy usou o termo plus value porque já estava disponível desde o século XVI na França, designando a diferença de valor (preço) entre duas operações, e que, em que pese a proximidade do termo com as noções de lucro, ganho, renda, etc, não era um termo adequado para expressar um conceito teórico novo, distinto das noções de exploração até então existentes. Pelo contrário, o uso de uma expressão como aquela constituiria até mesmo um obstáculo à compreensão do significado mais profundo da teoria.

Se essa tradução perdurou por cerca de um século, com uma aparente concordância de Marx, que inclusive revisou o texto, Balibar e Lefebvre especulam que foi porque ele, apesar de preferir usar vez ou outra o termo no original alemão, temia assustar os leitores franceses com jargões filosóficos alemães, e que, plus value poderia atender, ainda que não de forma plena, aos seus objetivos.

A discussão na França é um tanto quanto distinta da nossa, embora se assemelhe em substância. O imbróglio lá se concentra na parte inicial da expressão, sur (sobre) ou plus (mais), enquanto aqui é na parte final, na contraposição entre os complementos valia ou valor. Para reforçar seu argumento, Balibar e Lefebvre (1978, p. 36) destacam que Marx usou indistintamente o prefixo inglês surplus e o prefixo alemão nos Manuscritos de 185758 e 1861-63. Referindo-se a esse último, De Deus (2010a, p. 18) nos esclarece que o próprio Marx buscou se distanciar do sentido corrente do termo no idioma inglês:

$\mathrm{Na}$ abertura da obra, Marx explica que traduz a expressão inglesa "surplus value" para formular o termo Mehrwert, com sentido diverso dos ingleses. Ao longo do texto, empregará com frequência termos como Surplusarbeit e Surpluszeit como equivalentes de mais-trabalho (Mehrarbeit) e mais-tempo (Mehrzeit). Para diferenciar uma palavra da outra, utilizou-se o prefixo "sobre-" para traduzir "surplus" e "mais-" para traduzir "mehr".

Embora saiba desse procedimento de Marx, De Deus, em outro trabalho, defende o contrário, ou seja, a adoção do mais-valor como um termo que não esteja em sentido diverso do uso corrente pelos brasileiros.

\footnotetext{
"Mais-valor" representa, com efeito, termo mais rigoroso e segue a lógica da exposição marxiana, valor, valor de uso, valor de troca, mais-valor. Embora se trate de termo consagrado e até dicionarizado, "mais-valia" não parece ser o mais adequado na língua portuguesa: "valia", conquanto seja sinônimo de "valor", em certo sentido, não possui a mesma força compreensiva dessa última palavra e muito menos se concatena com as demais categorias da teoria marxiana. Em verdade, nada quer dizer para os ouvidos estranhos à tematização marxiana, enquanto maisvalor possui sentido imediato." (De Deus, 2010b, p. 05-06).
}

Os argumentos de Balibar e Lefebvre em favor do termo survaleur se assemelham aos nossos em defesa da mais-valia, como se verá alguns parágrafos à frente. Tendo em alguns momentos indicado a necessidade de se manter o sentido dominante

objeções de Gilbert Badia, também tradutor francês de Marx, à substituição de plus-value por survaleur, apoiado por Paul Boccara (Cornillet; Prost; Sève, 2010, p.265).” 
especificamente marxista do termo, sugerem que a expressão Mehrwert na França foi aburguesada ao tomar a forma de plus value, perdendo o sentido de transformação social que está associado ao termo. Segundo eles (1978, p. 38),

\begin{abstract}
"a teoria da mais-valia, como forma valor do sobretrabalho, não se limita a um simples jogo de associações verbais, mesmo que a língua teórica de Marx use desse procedimento. A realidade histórica da exploração e das lutas de classes de uma parte, e a exatidão da análise de Marx compensarão qualquer problema semântico."
\end{abstract}

Como se quisessem desequilibrar o debate convocando Marx para o seu time, esses autores recuperam trechos escritos por ele e Engels em prefácios, posfácios e cartas, nos quais manifestam concordância ou contrariedade com a tradução da obra para a língua francesa. Em carta a Danielson, de 28 de maio de 1872, Marx diz que "embora a edição francesa (traduzida pelo Senhor Roy, tradutor de Feuerbach) seja obra de um grande conhecedor das duas línguas, ele a traduziu demasiado literalmente. (Marx e Engels, 1974, p. 207)". No mesmo sentido, Engels lamenta a perda de elegância sofrida pela edição francesa em relação à alemã, citando a castração causada pela língua. Segundo ele, isso é causado pela "lógica formal pedante, que rouba da exposição tudo o que ela tem de impressionante e de vivo." (Marx e Engels, 1974, p. 210).

De fato, a expressão mais-valia perde em termos de literalidade na língua portuguesa, mas ganha por apresentar-se como um termo vivo, ${ }^{17}$ que requer explicação. Como se justificará mais adiante, pode estar aí sua vantagem. Comecemos por recordar às palavras do paladino do mais-valor:

Uma vez que não é tradução literal de "Mehrwert", o uso de "mais-valia" teria de ser justificado teoricamente. Essa tarefa é impossível, pois, como "valia" nada significa nesse contexto, não há como justificar "mais-valia" do ponto de vista teórico pela simples anteposição do advérbio. Ademais, além de ser uma tradução ilícita, a expressão "mais-valia" converte uma categoria de simples compreensão em algo enigmático, quase uma coisa. Produção capitalista, como se viu, é produção de valor, e produção de valor tem de ser produção crescente. Portanto, produção capitalista é, por definição, produção de mais-valor. Em síntese, nesta edição dos Grundrisse adotou-se "mais-valor" porque, além de ser a tradução literal de "Mehrwert", contribui para esclarecer o conteúdo da categoria." (Duayer, 2011a, p. 23).

Como já apontei anteriormente, tendemos a concordar com Duayer quando diz que é impossível formular uma justificativa teórica para o uso do termo mais-valia. Mas é preciso recordar que Marx tem sido até hoje criticado pelo uso de determinados termos ou nomes para suas categorias. Dificilmente pode se encontrar em Marx uma categoria cujo nome denote mais transparência que a exploração. A escolha desse termo não estimulou os potenciais oponentes de Marx a ler $O$ capital sem preconceitos. Pode-se dizer que a transparência do termo, pelo contrário, tem sido eficaz para repelir de imediato os conservadores que, ignorando o sentido do termo, imaginam que seja uma expressão de conteúdo moral ou apenas político em Marx. Sem dúvida, há um elemento político na

17 "De qualquer forma, o esqueleto da crítica, dado pela concepção materialista da história, estava posto. A teoria da mais-valia seria o elemento vivo, o que colocaria finalmente de pé a crítica da economia política." (Teixeira, 2014, p. 209). 
escolha do termo exploração, embora se deva dizer que um outro termo mais "técnico" poderia ter estimulado o diálogo com escolas do pensamento que se constituíam na época de Marx e logo após sua morte, como os marginalistas e austríacos, por exemplo. ${ }^{18}$

De fato, Marx não era afeito a concessões. Para ilustrar uma dessas pretensas adequações, deve-se dizer que na História do pensamento econômico a substituição do termo political economy (economia política) por economics (economia) representou mais do que uma inocente atualização semântica.

Por isso, quando Duayer e De Deus dizem que o uso do termo mais-valor "contribui para esclarecer o conteúdo da categoria", a pergunta que se impõe é: quem seriam os beneficiados? Nesse sentido, não é possível aceitar a ideia de que o termo mais-valia "converta uma categoria de simples compreensão em algo enigmático", pois ela, por sua própria natureza, não é uma categoria óbvia, de simples compreensão, como não foi para os socialistas ricardianos que já protestavam muito anos antes contra o excedente extraído dos trabalhadores, nem foi para o próprio Marx durante longa parte de sua trajetória teórica.

Ainda que, do ponto de vista político, fosse útil um nome mais próximo do seu significado popular, pode-se dizer que a mais-valia, do ponto de vista teórico, não tem que ser compreensível à primeira vista, pois não seria ele, o termo, a simplificar uma relação social de altíssima complexidade, envolvida por amplas camadas de mistificação. A complexidade é da própria sociedade capitalista. Por isso, não parece ser uma questão estrita de semântica, até porque, embora Duayer diga que "valia nada significa nesse contexto", um consorte seu reconhece que existe sinonímia entre valor e valia. (De Deus, 2010a, p. 17).

Outro elemento a ser pontuado é sobre os diferentes níveis de abstração. Valor e mais-valia estão em níveis mais abstratos que as categorias juros, lucro e renda. No nível de abstração em que aparece, que é na profundidade das relações de produção, ao contrário daquelas (juros, lucro e renda) que aparecem na superfície, o termo mais-valia apresentase mais adequado para espelhar o duplo aspecto apontado por Duayer ${ }^{19}$, marcando, dessa forma, nítida distinção quanto ao termo mais-valor, que por sua própria e estrita semântica, parece acentuar a relação de exploração apenas pelo seu aspecto quantitativo e pretensamente perceptível num nível menor de abstração. Fica, por assim dizer, esvaziado ou minimizado o sentido de estranhamento contido na relação capital-trabalho.

Se é possível fazer a associação que se segue, quando se diz que Marx tinha em 1848 todos os elementos da mais-valia ${ }^{20}$ - embora se sabe que só dez anos depois ele descobriria

\footnotetext{
18 A exagerada repulsa de Böhn-Bawerk a Marx pode ter sido bastante alimentada pelo conteúdo mais ontológico que técnico de expressões usadas por esse último.

19 "O mais-valor, contudo, além de desvendar o mecanismo de acumulação de capital, isto é, a expropriação do trabalhador, expressa um processo ainda mais fundamental: mais do que significar a exploração do trabalho, como de fato o faz, o mais-valor representa a objetivação, estranhada dos sujeitos, do potencial que possui o trabalho (social) de reproduzir de forma ampliada as suas condições antecedentes." (Duayer, 2011a, p. 21).

${ }^{20}$ Rosdolsky (2001, p. 20) diz que "em torno de 1848 estavam traçadas as linhas fundamentais da teoria da mais-valia". Mandel (1968, p. 56) tem opinião semelhante: "É em Trabalho Assalariado e Capital [de 1847] que Marx pressentiu pela primeira vez o essencial de sua teoria da mais-valia, sem utilizar esse termo e sem exprimir-se de maneira precisa.".
} 
a categoria, nos Grundrisse - o que Marx de fato tinha em 1848 era o mais-valor, a percepção de que havia uma relação de exploração, de subtração quantitativa do que era produzido pelo trabalhador. De fato, já em 1851, nos Cadernos de Londres $^{21}$, Marx demonstra ter se aproximado bastante da descoberta da mais-valia; o que restava era a tarefa de desenvolver a teoria em detalhes, que é o que foi feito nos Grundrisse e exposto em $O$ capital.

Insista-se nisto. Desde a Ideologia Alemã, Marx já tinha percebido que a chave explicativa estava na centralidade da exploração do trabalho como fundamento da produção de excedente. Com a descoberta da mais-valia nos Grundrisse o problema ainda não estava resolvido. Não se tratava, pois, de um imbróglio quanto à semântica adequada. Tratava-se de encontrar a forma adequada de exposição de uma categoria que significava mais do que um simples valor a mais extraído do trabalhador. Durante a elaboração dos Grundrisse, Marx indica ter percebido a complexidade dessa questão metodológica, conforme carta a Lassalle de 12 de novembro de 1858, em que diz que a demora no envio do manuscrito deveu-se principalmente ao seguinte fato: "tinha toda a matéria diante de mim, mas toda minha preocupação era com a forma." (Marx e Engels, 1983, p. 354).

Outra contraposição semelhante, e que expressa bem o nosso argumento, é a que Rosa e Gambi (2012, p. 15) fazem entre mais-valia e excedente:

\begin{abstract}
A mais-valia, grande descoberta científica de Marx, é a categoria mais adequada para mostrar como a exploração do trabalho na sociedade capitalista se realiza ontologicamente, isto é, independentemente da consciência dos homens. O excedente, por outro lado, parece uma fatia do bolo que excede, em média, as necessidades da sociedade. Não comparece, portanto, a pressuposição necessária da existência das classes no fundamento desta categoria. Não se enxerga nela que um lado da sociedade produz riqueza e o outro lado se apropria desta mesma riqueza.
\end{abstract}

O problema colocado para Marx passava a ser como entender dialeticamente a relação de troca entre trabalhador e capitalista, pela qual este pagava àquele o valor equivalente ao valor de sua força de trabalho, e, ao mesmo tempo, extraia um excedente em valor dessa relação. Era necessário operar o método dialético, já visando à exposição, missão para a qual Marx relata em carta a Engels de 14 de janeiro de 1858 ter sido de "... grande valia ter voltado a consultar [...] a Lógica de Hegel.” (Marx e Engels, 1983, p. 249).

Portanto, podemos dizer que o mais-valor gerado pelo trabalhador já era conhecido por Marx. Nisso não havia grande novidade em relação às relações de exploração existentes em sociedades anteriores. O desafio era mostrar as conexões profundas e não visíveis que conduziram a esse resultado na superfície, e é aí que uma categoria de outro nome, distinta do que se percebe apenas num nível mais concreto, embora também o englobe, torna-se

\footnotetext{
21 "Mas a renda pressuposta de toda classe proprietária tem que surgir na produção, e, portanto, ser de antemão uma dedução do lucro ou dos salários [...] Para que se aumente o valor do lucro, tem que haver um terceiro cujo valor se reduza. [...] Ele troca seu produto por outro cujo valor está determinado pelo tempo de trabalho nele empregado [...] O excedente não surge da troca, ainda que tão somente nela se realize. Surge de que deste produto que consome 20 dias de trabalho, o obreiro só obtém o produto de 10, etc., dias de trabalho." (Marx, 2006, p. 77).
} 
mais adequada para mostrar os dois aspectos citados. Se se reconhece que há uma relação de exploração por um lado, deve-se dizer que somente através da incorporação do aspecto de equivalência na mesma unidade dialética que engloba a não-equivalência, unidade esta que é a mais-valia, vai permitir que se compreenda a mistificação que envolve essa categoria e o consequente estranhamento.

Foi a elaboração teórica daquela unidade dialética que permitiu a Marx ultrapassar o universo conceitual em torno do excedente que ele já tinha alcançado em 1847 com $A$ miséria da filosofia. Por isso, diz Marx nos Grundrisse (2011, p. 255) que

[a mais-valia] ${ }^{22}$ é, no fundo, valor para além do equivalente. O equivalente, segundo sua determinação, é somente a identidade do valor consigo mesmo. [A mais-valia], consequentemente, jamais pode brotar do equivalente; portanto, tampouco pode brotar originariamente da circulação; tem de brotar do próprio processo de produção do capital.

O que é produzido pelo trabalhador vai ficando cada vez mais distante dele, mas ele se sente justiçado por ter feito uma troca justa no momento do contrato feito com o seu empregador. Por isso, de acordo com os argumentos apresentados, arrisca-se dizer que nos Grundrisse o que Marx descobriu não foi o mais-valor, e sim uma categoria mais completa que aquela, traduzida há anos entre nós por mais-valia, cuja exposição futura não ficaria mais ou menos clara em função do tipo de neologismo menos ou mais estranho.

Sendo assim, o suposto prejuízo semântico do uso da expressão mais-valia encontra sua compensação no sentido mais amplo do termo, que pretende não apenas apontar para uma mera exploração passível de ser combatida ou de ser atenuada, mas anunciar o advento de um modo de ser da sociedade que torna o trabalhador estranho ao produto do seu trabalho.

\section{Considerações Finais}

O que se quis argumentar, como ponto central neste artigo, é que a estranheza do termo mais-valia é fundamental. Ela carrega consigo um conteúdo social e histórico que não pode ser esvaziado. As abstrações feitas por Marx eram reais, concretas, expressão teórica de uma realidade social e histórica complexa. Não se trata apenas, portanto, de defender uma tradição, mas de defender o que é enigmático por si só, o que aparece de forma invertida, e que, portanto, não é discernível de imediato, encontrando, assim, na expressão mais-valia, uma forma mais adequada do que aquela que é aparentemente "compreensível". Se mais-valia significasse apenas não equivalência, exploração, concordaríamos com a mudança para um termo mais clarificado e insinuante. Mas, maisvalia, como categoria, é algo que ultrapassa o sentido da exploração, pois é composta também por um sentido de equivalência, sendo esta, como se depreende do capítulo 2 de $O$ capital, o ponto de partida da sua elaboração como categoria.

\footnotetext{
${ }^{22}$ Optamos por usar mais-valia em lugar da expressão mais-valor usada pelo tradutor dos Grundrisse, para não confundir a argumentação aqui desenvolvida.
} 
Por isso, o termo mais-valia, por ser menos familiar, por apontar para uma categoria que não resulta de uma apreensão direta da realidade e, portanto, não é óbvia, demonstrase mais adequado do que mais-valor, termo este - e aqui concordamos - mais eficiente na apreensão do sentido de exploração. Pelo prisma de um maior parentesco com o processo de produção de valor, no caso, como uma mera quantidade de valor que excede o valor da força de trabalho, o mais-valor mostrar-se-ia uma expressão mais adequada. Ao contrário de sociedades anteriores, em que os produtores detinham os meios de produção, o valor excedente perdeu historicamente qualquer parentesco com o proprietário da mercadoria força de trabalho, tornou-se estranho, e, nesse sentido, o valor que excede o valor da força de trabalho não é um simples arremedo do valor da força de trabalho ou do valor equivalente ao dos bens mínimos necessários à subsistência do trabalhador. O resultado do trabalho executado pelo trabalhador, ou seja, o produto, torna-se estranho a quem o produz.

Com efeito, mais do que mostrar uma mera continuidade na geração de valor durante a jornada de trabalho, Marx se notabilizou por mostrar o outro aspecto dessa contradição. Durante parte da jornada de trabalho, o trabalhador produz valor em montante equivalente ao valor do seu salário, "valor dos meios de subsistência necessários à manutenção do seu possuidor". (Marx, 1983a, 141). O valor que é gerado para além disso tem outra natureza. Portanto, usar o termo mais-valor para explicar o valor excedente em nada contribui para distingui-lo daquela etapa em que o trabalhador trabalha "para si mesmo".

Se por um lado, a mais-valia tem a mesma materialidade que o valor que foi criado na parte da jornada na qual se reproduziu o valor da força de trabalho, significando, dessa forma, apenas uma extensão de trabalho no tempo, por outro, aquele valor excedente apropriado por outrem é um dos principais elementos a distinguir a forma de ser de uma formação social histórica marcada tanto pela exploração do homem pelo homem quanto pela alienação do trabalho.

A categoria da mais-valia, portanto, tem o mérito da potencialidade de causar estranheza, e talvez, indignação. Ainda que tenha se preocupado em ser compreendido pelas massas populares, Marx nunca ignorou a dificuldade que os leitores não familiarizados com seus termos teriam para compreendê-la. Porém, assim como usou termos como exploração, querendo claramente provocar impacto sem deixar de ser científico, o termo mais-valia requer que não seja algo óbvio, natural, perfeitamente aceito, coerente com o estilo de um autor que repudiava as robinsonadas dos economistas clássicos.

Como termo meramente econômico, compreender-se-iam os benefícios do uso do termo mais-valor. Mas, foi apenas por ter uma compreensão rigorosamente dialética a respeito do funcionamento do capitalismo que Marx chegou à mais-valia. Como uma categoria que também se pretende filosófica, e que sintetiza uma época marcada pela ruptura entre o produtor e o produto do seu trabalho, o termo mais-valia, sendo descontínuo semanticamente em relação ao termo valor, pode ser mais capaz de representar aquela ruptura. Ademais, reproduziria mais precisamente os objetivos não somente científicos, como também ideológicos, de um autor que pretendia chamar a atenção para as injustiças e desigualdades do sistema capitalista. 
Se é verdade que Marx não queria, com a teoria da mais-valia, fazer ciência positiva, ou até mesmo uma mera crítica moral, deve-se dizer que o uso da expressão mais-valor tende a obnubilar até mesmo a elaboração, pelo próprio sentido do termo, de uma crítica com aquele fim. Ressalte-se o que já foi dito. A expressão mais-valor não é equivocada por si só ou pelo seu conteúdo etimológico, mas ela denota, insinua, dá a impressão de ser uma iniciativa que passa ao largo de toda a complexidade da categoria que Marx denominou como Merhwert, a nossa mais-valia. Talvez seja esse o principal defeito do termo maisvalor: passar despercebido, minimizando toda a complexa construção teórica que teve que se erigir em volta ou com base nele.

Continuaremos, enquanto possível, com a mais-valia, seja por entender que há méritos em resguardar a tradição das traduções brasileiras conhecidas há décadas, seja por entender (e esse é o ponto central) que o termo mais-valor, por excessivamente técnico, soa cândido demais, passível de passar despercebido o seu caráter ontológico, e assim, exalando suposta obviedade, ter efeito contrário ao não causar espécie nem nos que vierem a se iniciar no estudo de Marx, nem nos seus contumazes oponentes que estão sempre a apregoar que nada de novo se vê nele. Em suma, a impressão que se tem é que, ante a resistência à participação de Marx no debate econômico contemporâneo, a solução foi mudar o visual da desajeitada figura antiburguesa da mais-valia, vestindo-lhe a caráter para que o acesso à festa não lhe fosse mais negado; mera mudança de roupagem.

Convoquemos Clarice mais uma vez. "Cortar os defeitos pode ser perigoso - nunca se sabe qual o defeito que sustenta nosso edifício inteiro... é somente até certo ponto que a gente pode desistir de si própria e se dar aos outros e às circunstâncias."

A mais-valia precisa ser entendida como ponto fulcral de um longo processo de investigações movido tanto por uma insatisfação com a filosofia de seu tempo, quanto pela motivação político-ideológica de transformação socialista do mundo, representando a categoria-síntese, o núcleo fundamental da crítica da economia política, a partir do qual a essência da sociedade capitalista pôde ser revelada. 


\section{Referências Bỉbliográficas}

BALIBAR, E.; LEFEBVRE, J.P. Plus-value ou survaleur?. La Pensée, Paris, n.187, p. 32-42, février 1978.

COUTINHO, M. Marx: notas sobre a teoria do capital. São Paulo: Editora Hucitec, 1997.

DE DEUS, L. G. Apresentação. In: MARX, Karl. Para a crítica da economia política. Manuscrito de 1861-1863. Cadernos I a V. Terceiro capítulo - O capital em geral. Belo Horizonte, Autêntica Editora, 2010a, p. 09-19.

DE DEUS, L. Reconstrução Categorial de $\mathbf{O}$ Capital à luz de seus esboços. A instauração da crítica da economia política $(1857,1863)$. 259f. Tese (Doutorado em Economia) - Faculdade de Ciências Econômicas, Cedeplar, Universidade Federal de Minas Gerais. Belo Horizonte, 2010b.

DUAYER, M. Apresentação. In: MARX, Karl. Manuscritos econômicos de 1857-1858: esboços da crítica da economia política. São Paulo: Boitempo Editorial; Rio de janeiro: Ed. UFRJ, 2011a, p. 11-24.

DUAYER, M. 'Os Grundrisse foram um laboratório de pesquisa de Marx'.

Estadão.com.br, São Paulo, 25 de junho de 2011b. Entrevista concedida a Antonio Gonçalves Filho.

Disponível em: http://cultura.estadao.com.br/noticias/literatura,os-grundrisse-foram-umlaboratorio-de-pesquisa-de-marx,736837. Acesso em 20 jul. 2017.

DUAYER, M. Marx e a crítica ontológica da sociedade capitalista: crítica do trabalho. Em Pauta. Rio de Janeiro, Faculdade de Serviço Social da Universidade do Estado do Rio de Janeiro, n. 29, v. 10, 2012, p. 35-47. DOI: https://doi.org/10.12957/rep.2012.3880

DUSSEL, E. Hacia un Marx Desconocido. Un comentario de los Manuscritos del 61-63. Cidade do México: Siglo Veintiuno Editores, 2008.

GERMER, C.M.; NETO, P.L. da C. Em torno da tradução brasileira dos Grundrisse. Crítica Marxista. São Paulo, n. 34, p. 159-170, 2012.

HEINRICH, M. An Introduction to the three volumes of Karl Marx's Capital. Nova York: Monthly Review Press, 2004.

KOTHE, F.R.; SINGER, P.; BARBOSA, R. A Respeito da Tradução de O Capital. In: MARX, Karl. O Capital. Livro I, v. I. São Paulo: Editora Abril Cultural, 1983.

LESSA, S. Mais-valia. Disponível em: sergiolessa.com.br/uploads/7/1/3/3/71338853/maisvalia.docx. Acesso em: 25 ago. 2017. 
LUKÁCS, G. Para uma Ontologia do Ser Social. Rio de Janeiro: Editora Boitempo Editorial, v. 1, 2012.

MANDEL, E. A formação do pensamento econômico de Karl Marx. De 1843 até a redação de O CAPITAL. Rio de Janeiro: Zahar Editores, 1968.

MARX, K. Glosas Marginales al "Tratado de economia política" de Adolph Wagner. In: DOBB, Maurice (Org.). Estudios sobre El Capital. 4. ed., México: Siglo XXI, 1977.

MARX, K. O Capital. Livro I, v. I. São Paulo: Editora Abril Cultural, 1983a.

MARX, K. Prefácio da Edição Francesa. In: O Capital. Livro I, v. I. São Paulo:

Editora Abril Cultural, p. 23, 1983 b.

MARX, K. Teorias da Mais-Valia. Livro IV, v. III, São Paulo: Difel, 1985.

MARX, K. Salário, Preço e Lucro. In: . Para a Crítica da Economia Política.

Salário, Preço e Lucro. O Rendimento e suas Fontes. São Paulo: Abril Cultural, 2. ed., p. 133-179, 1986a.

MARX, K. Introdução [à Crítica da Economia Política]. In: Para a Crítica da Economia Política. Salário, Preço e Lucro. O Rendimento e suas Fontes. São Paulo: Abril Cultural, 2. ed., p. 03-21, 1986b.

MARX, K. Elementos Fundamentales para la Crítica de la Economía Política (Grundrisse) 1857-1858. V. 3. Madri: Siglo Veintiuno Editores, 13. ed., 2006.

MARX, K. Grundrisse. Manuscritos econômicos de 1857-1858: esboços da crítica da economia política. São Paulo: Boitempo Editorial; Rio de janeiro: Ed. UFRJ, 2011.

MARX, K.; ENGELS, F. Cartas sobre el capital. Barcelona: Laia, 1974.

MARX, K.; ENGELS, F. Collected Works. Moscou: Progress, v. 01, 1975.

MARX, K.; ENGELS, F. Werke. Berlim: Dietz, 1981. v. 1.

Disponível em:

https://marxwirklichstudieren.files.wordpress.com/2012/11/mew_band01.pdf.

MARX, K.; ENGELS, F. Collected Works. Moscou: Progress, v. 40, 1983.

MOSER, B. Clarice, São Paulo: Le Livros, 2013. Disponível em:

http://lelivros.stream/book/download-clarice-benjamin-moser-em-epub-mobi-e-pdf.

Acesso em: 18 mai. 2017.

PIRES, E. Mais-valia ou mais-valor?, 2011. Disponível em https://marxrevisitado.blogspot.com.br/2011/12/mais-valia-ou-mais-valor.html?m=0. Acesso em 20 jul. 2017. 
PRADO, E.F.S. Do dinheiro ao capital. Artigo 19, 2012. Sítio Pessoal. Disponível em: http://eleuterioprado.files.wordpress.com/2011/11/marx-do-dinheiro-ao-capital.pdf. Acesso em: 10 jul. 2017.

ROMANO, G.V. Nota preliminar del traductor. In: MARX, Karl. El capital. Madrid: Akal, 2007. p.7-13.

ROSA, E.R.; GAMBI, T. F. R. Excedente ou mais-valia? Discussão de fundamentos. In: XVII Encontro Nacional de Economia Política, 2012, Rio de Janeiro. Anais do XVII Encontro Nacional de Economia Política, 2012.

ROSDOLSKY, R. Gênese e estrutura de o capital de Karl Marx. Rio de Janeiro: EDUERJ: Contraponto, 2001.

SCARON, P. Advertencia del traductor. In: MARX, Karl. El capital. "El proceso de producción del capital”. Tomo I, v. 1. México. Siglo XXI, 1975, p. VII-XLI.

SCARON, P. Presentacion. In: MARX, Karl. Elementos Fundamentales para la Crítica de la Economía Política (Grundrisse) 1857-1858. V. 1. Madri: Siglo Veintiuno Editores, 13. ed., 2006, p. 7-10.

TEIXEIRA, A. L. A. A Genealogia da mais-valia: Filosofia, Economia e Crítica da Economia Política. 224f. Tese (Doutorado em Economia) - Faculdade de Ciências Econômicas, Cedeplar, Universidade Federal de Minas Gerais. Belo Horizonte, 2014.

TEIXEIRA, Adriano L. A. Definitivamente, Marx não foi um economista clássico! Marx e o Marxismo, v. 7, n. 13, jul/dez 2019.

TEIXEIRA, Aloísio. Marx e a economia política: a crítica como conceito. Econômica, n. 4. Rio de Janeiro: UFRJ/IEI, p. 85-109, 2000. 